\title{
Parameters affecting baseline hip function in patients with cam-derived femoroacetabular impingement syndrome: data analysis from the German Cartilage Registry
}

Sebastian Serong ${ }^{1 *}\left(\mathbb{D}\right.$, Moritz Schutzbach², Stefan Fickert ${ }^{3,4}$, Philipp Niemeyer ${ }^{5,6}$, Christian Sobau, Gunther Spahn ${ }^{8}$, Wolfgang Zinser ${ }^{9}$ and Stefan Landgraeber ${ }^{1}$

\begin{abstract}
Background: Using the database of the German Cartilage Registry (KnorpelRegister DGOU), this study aims to present patient- and joint-related baseline data in a large cohort of patients with cam-derived femoroacetabular impingement syndrome (FAl) and to detect symptom-determining factors.
\end{abstract}

Materials and methods: Requiring cam morphology as the primary pathology, 362 patients were found to be eligible for inclusion in the study. The assessment of preoperative baseline data was performed using the patient-reported outcome measure-International Hip Outcome Tool (iHOT-33). Descriptive statistics were performed to present baseline data. Univariate and multiple regression with post hoc testing were used to identify patient- and joint-related factors that might affect the preoperative iHOT-33 and its subscores, respectively.

Results: The study collective's mean age was $36.71 \pm 10.89$ years, with 246 (68\%) of them being male. The preoperative mean iHOT-33 total was $46.31 \pm 20.33$ with the subsection "sports and recreational activities" presenting the strongest decline (26.49 \pm 20.68$)$. The parameters "age," "sex," "body mass index" (BMI), and the confirmation of "previous surgery on the affected hip" were identified to statistically affect the preoperative iHOT-33. In fact, a significantly lower mean baseline score was found in patients aged $>40$ years $(p<0.001)$, female sex $(p<0.001), \mathrm{BMl} \geq 25 \mathrm{~kg} / \mathrm{m}^{2}$ $(p=0.002)$ and in patients with previous surgery on the affected hip $(p=0.022)$. In contrast, the parameters defect grade and size, labral tears, and symptom duration delivered no significant results.

Conclusions: A distinct reduction in the baseline iHOT-33, with mean total scores being more than halved, was revealed. The parameters "age $>40$ years," "female sex," "BMI $\geq 25$," and confirmation of "previous surgery on the affected hip" were detected as significantly associated with decreased preoperative iHOT-33 scores. These results help to identify symptom-defining baseline characteristics of cam-derived FAl syndrome.

Trial registration: The German Cartilage Registry is conducted in accordance with the Declaration of Helsinki and registered at germanctr.de (DRKS00005617). Registered 3 January 2014-retrospectively registered. The registration of data was approved by the local ethics committees of every participating institution. Primary approval was given by the

\footnotetext{
*Correspondence: sebastian.serong@uks.eu

1 Department of Orthopaedics \& Orthopaedic Surgery, Saarland

University Medical Centre, Kirrberger Strasse 100, 66421 Homburg,

Germany

Full list of author information is available at the end of the article
}

(c) The Author(s) 2021. Open Access This article is licensed under a Creative Commons Attribution 4.0 International License, which permits use, sharing, adaptation, distribution and reproduction in any medium or format, as long as you give appropriate credit to the original author(s) and the source, provide a link to the Creative Commons licence, and indicate if changes were made. The images or other third party material in this article are included in the article's Creative Commons licence, unless indicated otherwise in a credit line to the material. If material is not included in the article's Creative Commons licence and your intended use is not permitted by statutory regulation or exceeds the permitted use, you will need to obtain permission directly from the copyright holder. To view a copy of this licence, visit http://creativecommons.org/licenses/by/4.0/. 
ethics committee at the University of Freiburg (No. 105/13). https://www.drks.de/drks_web/navigate.do?navigation Id =trial.HTML\&TRIAL_ID=DRKS00005617

Keywords: Femoroacetabular impingement syndrome, Cam morphology, iHOT-33, Baseline data, Patient-reported outcome

\section{Introduction}

Over the last two decades, cam morphology and the associated femoroacetabular impingement syndrome (FAI) have been identified as a common source of hip pain and premature cartilage damage [1-4]. Although its pathogenesis is not yet fully understood, considerable progress has been made regarding various factors surrounding this pre-arthritic bony malformation. It is known that camtype FAI predominantly affects young and active males, especially those participating in high-level impact sports [5-8]. In these patients, alterations in the capital femoral epiphysis, presumably a response to repetitive sportsrelated microtrauma, are regularly detected $[9,10]$. Due to the pathological anatomy of the head-neck junction, cam-derived cartilage defects are typically found on the acetabular side of the joint $[11,12]$. In this connection, labral tears are a further common finding in patients with cam morphology $[13,14]$.

The symptoms commonly described in cases of symptomatic FAI include motion-related or position-related pain in the hip and groin and functional limitations such as a reduced range of motion and even alterations in gait parameters $[7,15,16]$. For better evaluation of hip function in general, the patient-reported International Hip Outcome Tool (iHOT-33) was introduced in 2012. The iHOT-33 is a self-administered evaluative questionnaire to measure health-related quality of life in individuals with hip disorders [17]. Among other patient-reported outcome measures (PROMs), it has been proven to be reliable and highly responsive to clinical change and is therefore used regularly worldwide [18-22]. The iHOT33 comprises 33 items that are categorized into four thematic sections: "symptoms and functional limitations," "sports and recreational activities," "job-related concerns," and "social, emotional and lifestyle concerns."

To reliably evaluate pre- and postoperative hip function in patients with chondral defects due to multiple causes, the iHOT-33 is also used in the German Cartilage Registry (KnorpelRegister DGOU). This multicenter, nationwide register aims at collecting baseline and follow-up data in connection with the treatment of osteochondral defects of the hip, as well as the knee and the ankle joint.

Concerning the parameters affecting hip function in patients with symptomatic FAI in general and with camderived FAI in particular, studies usually focus on the assessment of therapy outcome. In these studies, several factors, such as age, sex, or body mass index (BMI), that influence treatment results have so far been identified [23-26]. However, little is known about the factors that determine preoperative symptoms. It is to be hypothesized that parameters found to be influential on the treatment outcome also determine functional limitations preoperatively. Therefore, this study's purpose is to present patient- and joint-related baseline data in a large cohort of patients with symptomatic femoroacetabular impingement syndrome (FAI) due to cam morphology and to detect symptom-determining factors.

\section{Materials and methods}

Data for the present study were taken from the German Cartilage Registry (KnorpelRegister DGOU). The German Cartilage Registry is a multicenter register with over 70 participating clinics that was set up in 2013 to evaluate the long-term outcomes of different methods of surgical cartilage repair on the hip, knee, and ankle joint. The registry is conducted in accordance with the Declaration of Helsinki and was registered in the German Clinical Trials Register. Approval was received from each ethics committee before the enrollment of the first patients. The participants were generally included prior to surgery with informed consent given by every patient. Data collection was performed via web-based input.

Up to August 2019, the registry's subsection "hip" contained data from 1461 patients that underwent hip surgery, particularly for reasons of cartilage damage. To solely assess patients with cam-derived FAI, only patients with documentation of isolated cam morphology that was declared causal of cartilage damage were included. Patients with record of other or multiple hip pathologies were excluded. With regard to FAI in particular, cases of isolated Pincer- or combined Cam-/Pincer morphology were excluded as well, though, in cases of isolated cam morphology, cartilage damage and labral tears were judged as cam-derived and consequently kept for evaluation. Further exclusion was made on the basis of missing documentation of the cartilage status. Consequently, 551 patients were generally considered eligible for inclusion. However, as several entries presented with incomplete datasets, these were excluded as well, ultimately resulting in 362 patients to form the final study group. Detailed information on the inclusion/exclusion procedure is provided in Fig. 1. A sample size of 362 produces a two-sided 


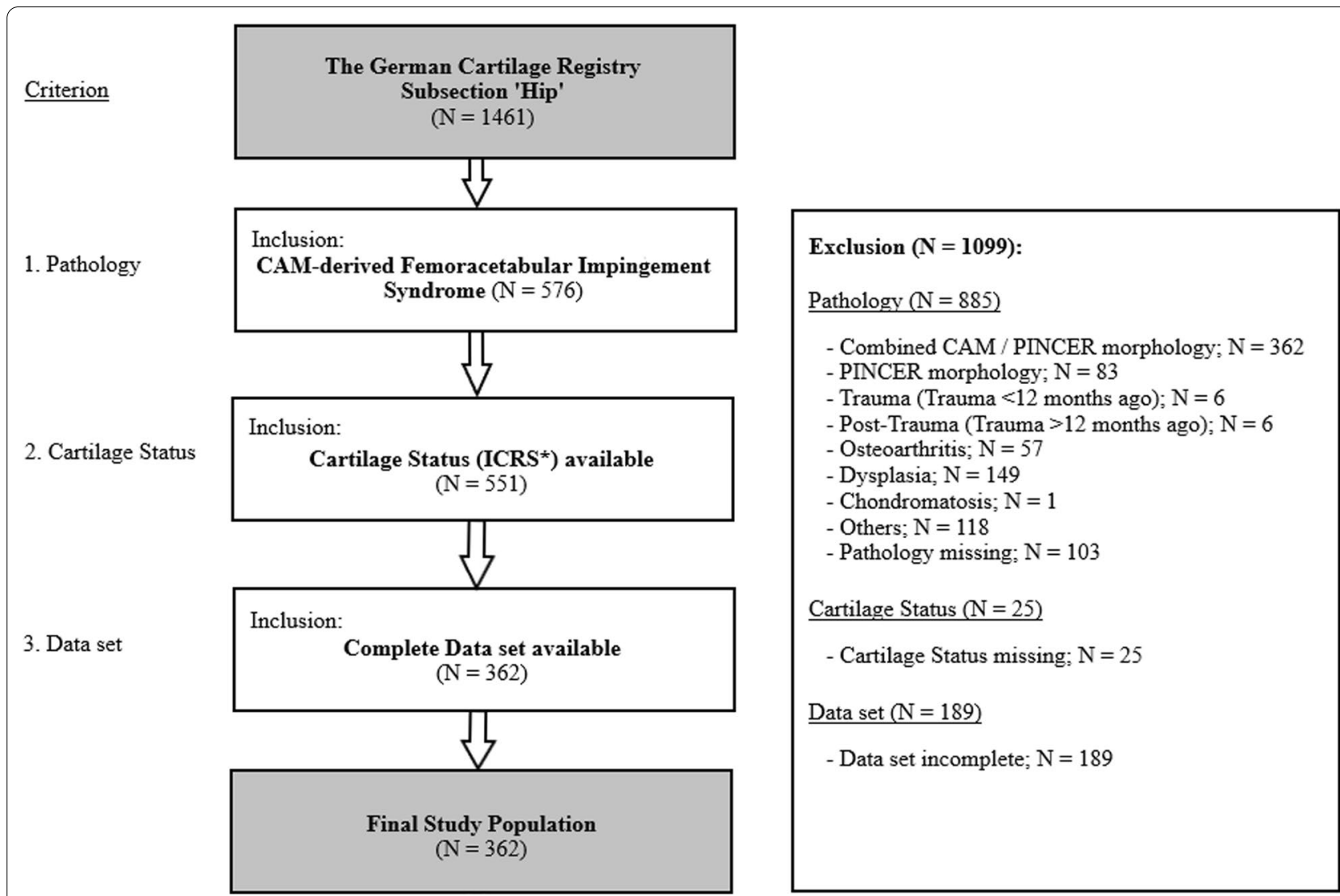

Fig. 1 Selection procedure for the study group on the basis of the subsection "hip" of the German Cartilage Registry; ICRS*-International Cartilage Repair Society

$95 \%$ confidence interval with a distance from the mean to the limits that is equal to 2.6 when the estimated standard deviation of preoperative $\mathrm{iHOT}-33$ total is 25 points.

General patient data as well as pre- and postoperative data collection was performed via web-based remote data entry system. Perioperative data, including defect- and joint-specific characteristics, procedure-related information, and diagnosis confirmation, were provided by the treating surgeon on the basis of the intraoperative findings. Except one open procedure, all other study patients were treated by means of hip arthroscopy $(n=259)$ or arthroscopically assisted $(n=94)$. Overall hip function was measured using the iHOT-33 and its subsections. The total scores, as well as the subscores, were calculated as a mean of the specific item responses ranging from 0 to 100 , with 100 representing the best possible quality-oflife score. Only preoperative baseline data were used in this analysis.

Statistical analysis was performed using SPSS Statistics (Version 21.0.0.0, IBM). Descriptive data are presented as mean ( \pm standard deviation (SD) and 95\% confidence intervals $(\mathrm{CI})$ ), percentage of the total and in total numbers. To detect factors possibly affecting preoperative iHOT-33, univariate and multiple regression analysis with simultaneous entry was performed. Metric and dichotomous variables were directly entered in the regression model; categorical variables were dummy coded first. Post hoc Tukey's test and Student's $t$-test were used to evaluate the subgroups of statistically influencing variables. The two-sided level of significance was set at $p \leq 0.05$.

\section{Results}

\section{Baseline data}

Sex distribution of the study group was nearly 2:1 (male versus female), with an overall mean age of 36.71 $( \pm 10.89)$ years. The mean symptom duration at the date of surgery was $23.42( \pm 23.02)$ months. Three patients $(0.8 \%)$ presented with isolated femoral cartilage damage. All other study participants had isolated acetabular $(n=119 / 32.9 \%)$ or multilocular $(n=240 / 66.3 \%)$ cartilage lesions. Concomitant labral tears were found in 319 patients $(88.1 \%)$. Detailed patient characteristics are presented in Table 1. 
Table 1 Baseline data of the study group's patient- and joint-specific characteristics

\begin{tabular}{ll}
\hline Parameter & Mean \pm SD or $\boldsymbol{n}(\%)$ \\
\hline Age, years & $36.71 \pm 10.89$ \\
Sex, male/female & $246(68.0 \%) / 116(32.0 \%)$ \\
Smoking status, non-smoker/smoker/ex-smoker & $274(75.7 \%) / 78(21.5 \%) / 10(2.8 \%)$ \\
Body mass index, $\mathrm{kg} / \mathrm{m}^{2}$ & $24.90 \pm 3.61$ \\
Previous surgery on the affected hip, no/yes & $336(92.8 \%) / 26(7.2 \%)$ \\
Cartilage defect grade (ICRS*), I/ll/lla and b//Va and b & $40(11.0 \%) / 103(28.5 \%) / 153(42.3 \%) / 66(18.2 \%)$ \\
Cartilage defect size, $\mathrm{mm}^{2}$ & $157.76 \pm 204.86$ \\
Labral tear (\% of vertical diameter), none/<33/33-66/>66 & $43(11.9 \%) / 88(24.3 \%) / 96(26.5 \%) / 135(37.3 \%)$ \\
Number of chondral defects, 1/2/3 & $313(86.5 \%) / 37(10.2 \%) / 12(3.3 \%)$ \\
Symptom duration, months & $23.42 \pm 23.02$ \\
\hline
\end{tabular}

$S D$ standard deviation, ICRS* International Cartilage Repair Society

Table 2 Baseline data of the study group's iHOT-33 total and subscores

\begin{tabular}{ll}
\hline $\begin{array}{l}\text { International Hip Outcome Tool (iHOT- } \\
\text { 33) }\end{array}$ & Mean \pm SD (95\% Cl) \\
\hline Total & $46.31 \pm 20.33(43.21-48.41)$ \\
Symptoms and functional limitations & $54.73 \pm 23.36(52.31-57.14)$ \\
Sports and recreational activities & $26.49 \pm 20.68(24.34-28.63)$ \\
Job-related concerns & $49.37 \pm 29.33(45.98-52.76)$ \\
Social, emotional, and lifestyle concerns & $43.33 \pm 23.99(40.85-45.81)$
\end{tabular}

$S D$ standard deviation, $\mathrm{Cl}$ confidence interval
The study group's preoperative iHOT-33 total was $46.31( \pm 20.33)$. The corresponding subscores were also distinctly lowered, with the greatest decrease for the "sports and recreational activities" score (Table 2).

\section{Influencing factors}

Univariate and multiple regression analysis were performed to detect symptom-influencing factors in preoperative patients with cam-type FAI syndrome. The variables included and the corresponding statistical results are listed in Table 3. Particularly, multiple

Table 3 Univariate and multiple regression of parameters with possible influence on baseline iHOT-33

\begin{tabular}{|c|c|c|}
\hline \multirow[t]{2}{*}{ Parameter } & \multicolumn{2}{|l|}{ Baseline iHOT-33 } \\
\hline & Univariate regression & Multiple regression \\
\hline Age & $\begin{array}{l}p<0.001^{* * *} \\
\beta=-0.293\end{array}$ & $\begin{array}{l}p<0.001^{* * *} \\
\beta=-0.203\end{array}$ \\
\hline Sex (1 male, 2 female) & $\begin{array}{l}p<0.001^{* * *} \\
\beta=-0.293\end{array}$ & $\begin{array}{l}p<0.001^{* * *} \\
\beta=-0.311\end{array}$ \\
\hline Smoking status & $\begin{array}{l}\text { Not significant } \\
(p=0.114)\end{array}$ & $\begin{array}{l}\text { Not significant } \\
(p=0.122)\end{array}$ \\
\hline Body mass index & $\begin{array}{l}p=0.023^{*} \\
\beta=-0.120\end{array}$ & $\begin{array}{l}p=0.030^{*} \\
\beta=-0.120\end{array}$ \\
\hline Previous surgery on the affected hip & $\begin{array}{l}p=0.022^{*} \\
\beta=-0.121\end{array}$ & $\begin{array}{l}p=0.003^{* *} \\
\beta=-0.151\end{array}$ \\
\hline Cartilage defect grade (ICRS*) & $\begin{array}{l}\text { Not significant } \\
(p=0.178)\end{array}$ & $\begin{array}{l}\text { Not significant } \\
(p=0.405)\end{array}$ \\
\hline Cartilage defect size & $\begin{array}{l}\text { Not significant } \\
(p=0.949)\end{array}$ & $\begin{array}{l}\text { Not significant } \\
(p=0.622)\end{array}$ \\
\hline Labral tear & $\begin{array}{l}\text { Not significant } \\
(p=0.893)\end{array}$ & $\begin{array}{l}\text { Not significant } \\
(p=0.534)\end{array}$ \\
\hline Number of defects & $\begin{array}{l}\text { Not significant } \\
(p=0.787)\end{array}$ & $\begin{array}{l}\text { Not significant } \\
(p=0.125)\end{array}$ \\
\hline Symptom duration & $\begin{array}{l}\text { Not significant } \\
(p=0.206)\end{array}$ & $\begin{array}{l}\text { Not significant } \\
(p=0.279)\end{array}$ \\
\hline
\end{tabular}

ICRS* International Cartilage Repair Society, $p p$ value, $\beta$ regression coefficient ${ }^{*} p \leq 0.05,{ }^{* *} p \leq 0.01,{ }^{* * *} p \leq 0.001$ 
regression revealed four factors to be statistically significantly associated with higher preoperative iHOT33 scores: "younger patient age" $(p<0.001)$, "male sex" $(p<0.001)$, "lower BMI" $(p=0.030)$, and the absence of "previous surgeries on the affected hip" $(p=0.003)$. All other analyzed parameters were shown to be not significantly associated with certain tendencies in iHOT-33 scoring, among others, the cartilage parameters "defect size" $(p=0.622)$ and "defect grade" $(p=0.405)$, the presence of "labral tears" $(p=0.534)$, and the overall "symptom duration" ( $p=0.279)$ (Table 3).

Descriptive statistics for the parameter "age" revealed that increasing patient age almost constantly decreases the mean baseline iHOT-33 (Fig. 2). Here, the age of 40 years sets a distinct limit, with younger patients having a significantly better iHOT-33 than older patients (50.81 ( \pm 19.65$)$ versus 39.50 ( \pm 19.49$), p<0.001)$.

Analysis of the parameter "sex" showed males to have a mean preoperative iHOT-33 of $50.61( \pm 18.78)$ compared with $37.20( \pm 20.55)$ for females $(p<0.001)$. For "age" and "sex," results showed a similar pattern for the according subscores except for "sports and recreational activities." As lower BMI was revealed to be positively associated with higher iHOT-33 scores, the study collective was subdivided according to the categories proposed by the World Health Organization (WHO). Study patients with a BMI below pre-obesity $\left(<25 \mathrm{~kg} / \mathrm{m}^{2}\right)$ were proven to have significantly better baseline iHOT scores than those with a BMI $\geq 25 \mathrm{~kg} / \mathrm{m}^{2}(49.26 \pm 19.67$ versus $42.72 \pm 20.59, p=0.002)$. Regarding "previous surgery on the affected hip," patients without previous operations had a mean preoperative iHOT-33 of 46.99 ( \pm 20.26$)$, whereas those with previous hip surgery in their medical history had a significantly lower mean score of 37.51 $( \pm 19.46 ; p=0.022)$. Detailed statistics of the affecting parameters are presented in Table 4.

\section{Discussion}

This study's results demonstrate the distinct reduction of function-related parameters due to cam-derived FAI syndrome. In particular, the parameters "age $>40$ years," "female sex," "BMI > 25", and "previous surgery on the affected hip" were identified as associated with statistically significantly lowered scores in preoperative baseline iHOT-33.

With " 100 " representing the best possible quality-oflife score, the mean iHOT-33 in the study cohort was less than half, indicating the severity of FAI-associated health restrictions. Even greater deteriorations were found for the sports and recreational activities subscore. These findings generally correlate with those in the current literature. However, this study's baseline iHOT tends to be higher when compared with Nwachukwu et al., who reported preoperative iHOT scores of 39.7 and 40.6, respectively in own FAI collectives [27, 28]. Griffin et al. reported an even lower baseline iHOT-33 of 35.6 when assessing patients with symptomatic FAI prior to conservative treatment [29]. With regard to other PROMS, reported preoperative and "preconservative" values of the Hip Outcome Score-Activities of Daily Living (HOS$\mathrm{ADL}$ ) tend to be higher, with results ranging from 65.7 to $73.9[26-28,30]$, though the distinct baseline reduction of the sport-specific subscale (HOS-SSS) in comparison with the HOS-ADL confirms this study's findings regarding the poor sports-specific iHOT subscores [26-28]. To appropriately interpret this finding, one has to consider

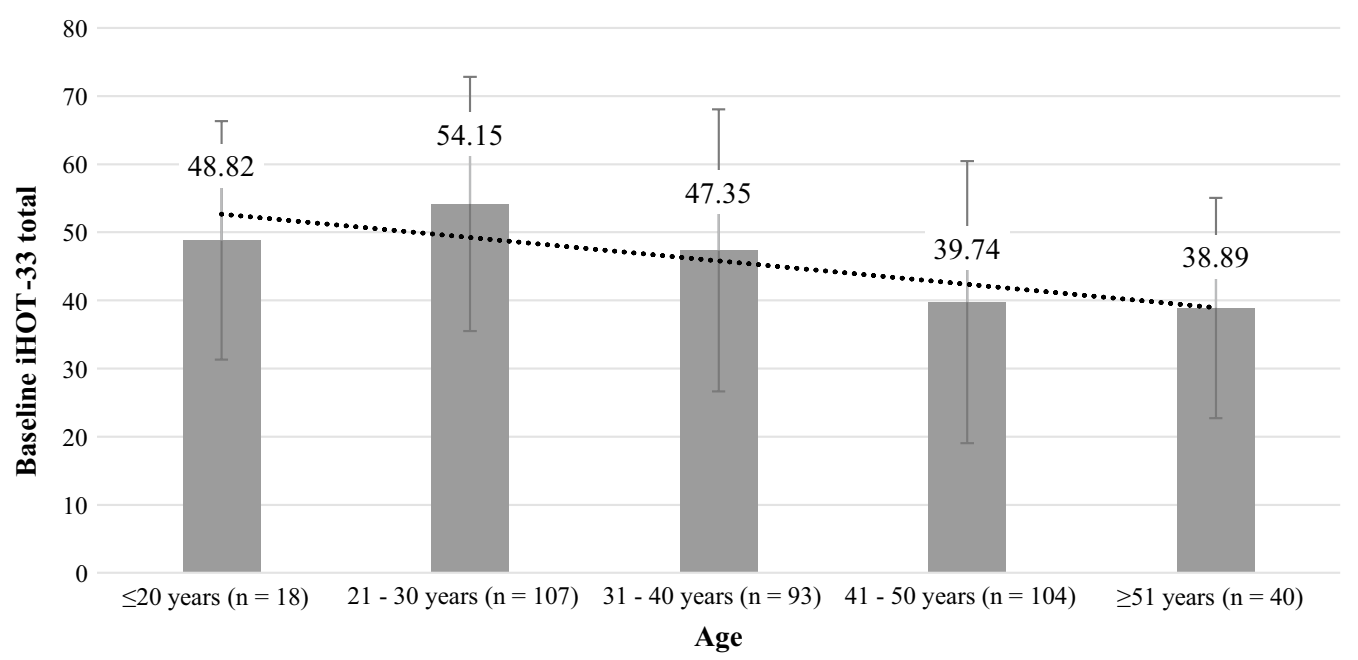

Fig. 2 Age-dependent decrease of mean baseline score of the 33-item International Hip Outcome Tool (iHOT-33) 
Table 4 Parameter-dependent differences in iHOT-33 total and subscores with statistical analysis using post hoc Tukey's and Student's t test

\begin{tabular}{|c|c|c|c|c|c|}
\hline \multirow[t]{3}{*}{ Parameter } & \multicolumn{5}{|l|}{ Baseline iHOT-33 } \\
\hline & Total & $\begin{array}{l}\text { Symptoms and } \\
\text { functional limitations }\end{array}$ & $\begin{array}{l}\text { Sports and recreational } \\
\text { activities }\end{array}$ & Job-related concerns & $\begin{array}{l}\text { Social, emotional, and } \\
\text { lifestyle concerns }\end{array}$ \\
\hline & \multicolumn{5}{|l|}{ Mean \pm SD $(95 \% \mathrm{Cl})$} \\
\hline \multicolumn{6}{|l|}{ Age } \\
\hline$\leq 40$ years & $\begin{array}{l}50.81 \pm 19.65(48.19- \\
53.43)\end{array}$ & $\begin{array}{l}60.62 \pm 22.33(57.64- \\
63.60)\end{array}$ & $\begin{array}{l}27.18 \pm 21.11(24.36- \\
30.00)\end{array}$ & $\begin{array}{l}56.92 \pm 28.66(52.66- \\
\quad 61.19)\end{array}$ & $\begin{array}{l}46.96 \pm 23.29(43.85- \\
50.07)\end{array}$ \\
\hline \multirow[t]{2}{*}{$>40$ years } & $\begin{array}{l}39.50 \pm 19.49(36.29- \\
42.71)\end{array}$ & $\begin{array}{l}45.80 \pm 22.09(42.16- \\
49.44)\end{array}$ & $\begin{array}{l}25.42 \pm 20.02(22.10- \\
28.75)\end{array}$ & $\begin{array}{l}37.72 \pm 26.49(32.80- \\
42.63)\end{array}$ & $\begin{array}{l}37.82 \pm 24.07(33.86- \\
41.78)\end{array}$ \\
\hline & $p<0.001^{* * *}$ & $p<0.001^{* * *}$ & $p=0.432$ & $p<0.001^{* * *}$ & $p<0.001^{* * *}$ \\
\hline \multicolumn{6}{|l|}{ Sex } \\
\hline Male & $\begin{array}{l}50.61 \pm 18.78(48.25- \\
52.97)\end{array}$ & $\begin{array}{l}60.35 \pm 21.00(57.71- \\
62.98)\end{array}$ & $\begin{array}{l}27.77 \pm 21.46(25.06- \\
30.47)\end{array}$ & $\begin{array}{l}54.11 \pm 28.72(50.07- \\
58.16)\end{array}$ & $\begin{array}{l}47.05 \pm 23.49(44.10- \\
50.00)\end{array}$ \\
\hline \multirow[t]{2}{*}{ Female } & $\begin{array}{l}37.20 \pm 20.55(33.42- \\
\quad 40.98)\end{array}$ & $\begin{array}{l}42.81 \pm 23.74(38.44- \\
\quad 47.17)\end{array}$ & $\begin{array}{l}23.80 \pm 18.72(20.35- \\
27.24)\end{array}$ & $\begin{array}{l}39.49 \pm 28.24(33.71- \\
\quad 45.28)\end{array}$ & $\begin{array}{l}35.43 \pm 23.21(31.16- \\
39.70)\end{array}$ \\
\hline & $p<0.001^{* * *}$ & $p<0.001^{* * *}$ & $p=0.074$ & $p<0.001^{* * *}$ & $p<0.001^{* * *}$ \\
\hline \multicolumn{6}{|c|}{ Body mass index } \\
\hline$<25 \mathrm{~kg} / \mathrm{m}^{2}$ & $\begin{array}{l}49.26 \pm 19.67(46.51- \\
52.01)\end{array}$ & $\begin{array}{l}58.75 \pm 22.64(55.58- \\
\quad 61.91)\end{array}$ & $\begin{array}{l}27.57 \pm 19.90(24.79- \\
30.36)\end{array}$ & $\begin{array}{l}53.57 \pm 28.31(49.16- \\
57.98)\end{array}$ & $\begin{array}{l}44.71 \pm 23.06(41.49- \\
\quad 47.94)\end{array}$ \\
\hline \multirow[t]{2}{*}{$\geq 25 \mathrm{~kg} / \mathrm{m}^{2}$} & $\begin{array}{l}42.72 \pm 20.59(39.53- \\
45.90)\end{array}$ & $\begin{array}{l}49.82 \pm 23.36(46.20- \\
53.43)\end{array}$ & $\begin{array}{l}25.14 \pm 21.59(21.78- \\
28.50)\end{array}$ & $\begin{array}{l}44.13 \pm 29.83(38.94- \\
49.33)\end{array}$ & $\begin{array}{l}41.63 \pm 25.06(37.76- \\
45.51)\end{array}$ \\
\hline & $p=0.002^{* *}$ & $p<0.001^{* * *}$ & $p=0.268$ & $p=0.006^{* *}$ & $p=0.224$ \\
\hline \multicolumn{6}{|c|}{ Previous surgery } \\
\hline No & $\begin{array}{l}46.99 \pm 20.26(44.82- \\
\quad 49.17)\end{array}$ & $\begin{array}{l}55.56 \pm 23.14(53.07- \\
58.04)\end{array}$ & $\begin{array}{l}26.79 \pm 21.05(24.53- \\
29.07)\end{array}$ & $\begin{array}{l}49.40 \pm 29.53(45.87- \\
52.93)\end{array}$ & $\begin{array}{l}44.05 \pm 24.05(41.47- \\
\quad 46.63)\end{array}$ \\
\hline \multirow[t]{2}{*}{ Yes } & $\begin{array}{l}37.51 \pm 19.46(29.65- \\
45.37)\end{array}$ & $\begin{array}{l}43.97 \pm 24.01(34.27- \\
53.67)\end{array}$ & $\begin{array}{l}22.59 \pm 14.92(16.56- \\
28.61)\end{array}$ & $\begin{array}{l}48.99 \pm 27.05(35.95- \\
62.03)\end{array}$ & $\begin{array}{l}33.91 \pm 21.58(25.20- \\
42.63)\end{array}$ \\
\hline & $p=0.022^{*}$ & $p=0.015^{*}$ & $p=0.191$ & $p=0.950$ & $p=0.029^{*}$ \\
\hline
\end{tabular}

$S D$ standard deviation, $C l$ confidence interval, $p p$ value

${ }^{*} p \leq 0.05,{ }^{* *} p \leq 0.01,{ }^{* * *} p \leq 0.001$

the Patient Acceptable Symptomatic State (PASS) related to hip arthroscopy and FAI. In this context, Maxwell et al. reported a PASS score of 58 points for the iHOT-33 at 2 years follow-up after hip arthroscopy [31]. Using the 12-item iHOT, Robinson et al. recently reported a PASS threshold of 59.5 points following arthroscopy for FAI in a UK population [32]. So, as both identified PASS scores were distinctly undercut by the study group's mean preoperative score, this additionally underlines the clinical relevance of functional limitations in this context. However, one also has to be aware that these limitations could not only be cam-derived as concomitant cartilage and labrum defects might have contributed as well. As concerns the iHOT-33 associated subscores, all except "symptoms and functional limitations" were reduced by more than half as well. The greatest reductions were seen for "sports and recreational activities." However, this is not surprising as the evaluated patient collective was rather young. It appears likely that sports activities play an important role in their everyday lives and that, therefore, their general level of activity is higher compared with older people [33, 34]. In this context, it was Agricola et al. who described the development of cam morphology in adolescent athletes before growth plate closure $[5,35]$. Further confirmation of this concept was provided by Palmer et al., who also depicted the underlying causality with physical activities and particularly emphasized the risk of developing secondary hip pathology after the occurrence of cam deformity [36]. Altogether, it can be reasonably assumed that, due to the combination of younger patients' age and the performance of sports activities, functional limitations become especially apparent in the iHOT's sports-specific subscore and are accompanied by a relevant reduction in the overall quality of life [37]. Moreover, not only the confirmation of sports activities alone but rather the level of its performance appears to be of importance. Compared with recreational athletes, high-level athletes have a higher likelihood of undergoing bilateral surgery in the case of symptomatic FAI [38]. 
In total, this study's results were generally to be expected since the symptoms related to FAI are well known. Nevertheless, publications assessing preoperative baseline-data in depth are rare. This study's findings enable quantification and identification of the core areas of preoperative functional limitations in cam-type FAI using the standardized and reliable iHOT-33 [17]. Furthermore, through the use of register data, the findings are based on a large, multicenter patient collective.

This study's second objective was to identify factors that may influence preoperative hip function in patients with FAI due to cam morphology. Again, the iHOT-33 was taken as a measure for quantification of joint-related functional restrictions. Using univariate and multiple regression analysis, four factors were detected to be significantly correlated to the preoperative iHOT-33 score. These were the parameters "age," "sex," "body mass index," and the confirmation of "previous surgeries on the affected joint." In fact, the factors younger age, male sex, BMI $<25 \mathrm{~kg} / \mathrm{m}^{2}$, and the absence of previous surgical treatment delivered significantly better results regarding the preoperative iHOT-33 scores. Interestingly, except for joint-related previous surgeries, these parameters were exactly the same as those recently identified by Sogbein et al., which confirms the initially proposed hypothesis. In their review on the predictors of outcome after arthroscopy for FAI, the above parameters were explicitly declared as predictors of a positive outcome [23]. Furthermore, their reported outcome-dependent thresholds concerning the patients' age $(<45$ years $)$ and the BMI $\left(<24.5 \mathrm{~kg} / \mathrm{m}^{2}\right)$ correspond very closely with this study's findings as ages $<40$ years and $\mathrm{BMI}<25 \mathrm{~kg} / \mathrm{m}^{2}$ had a significantly better baseline iHOT-33 total. Apart from this, there are further publications that indicate the influential role of patients' sex, age, and BMI on FAI-related treatment outcome [26, 39-41]. This suggests that there is a considerable overlapping of factors influencing postoperative results and those affecting preoperative function and symptoms in the FAI syndrome. This is of relevance insofar as the majority of publications focus on the presentation of outcome data to evaluate treatment success [23-26, 39-41]. As mentioned above, little has been published on baseline data. But these data might help physicians gain a better understanding of the pathology of FAI and particularly the underlying cam morphology as a whole. In this context, this study's results are supported by the findings of Nwachukwu et al., who also detected lower preoperative PROMs and patient-reported outcomes measurement information system scores (PROMIS) for the female sex and a higher BMI [42]. However, as statistical findings are not necessarily associated with clinical relevance, it was also Nwachukwu et al. who identified the iHOT-33's minimal clinically important difference (MCID) after arthroscopic treatment of FAI syndrome at 12.1. [28] In light of that and with regard to the iHOT-33 total, only the sex-dependent preoperative mean difference was shown to exceed this threshold, though the age-dependent mean differences only narrowly missed passing the MCID.

As concerns the factors identified to possibly influence the baseline iHOT, it is known that the ageing of organisms is accompanied by an ongoing reduction in the ability of tissues to maintain themselves [43]. Obviously, this also affects joint-related tissue such as bone and cartilage where the deviant behavior of chondrocytes during the ageing process has been proven [44]. Therefore, it is comprehensible that increasing age is accompanied by lower functional scores pre- and postoperatively $[13,23,26,39$, 40]. In this context, 40-45 years of age seem to mark a threshold [23]. With regard to sex as an affecting parameter, its role is not yet fully understood. Sogbein et al. postulated a possibly underlying laxity in female soft tissue that might affect postoperative results [23]. As this is a permanent state, it could affect preoperative function and symptoms as well. However, this is highly speculative and needs to be further investigated. Body mass index has been controversially discussed concerning its role in hip arthroscopy and FAI syndrome. Several publications have reported the negative impact of obesity on the outcome of arthroscopic treatment in general [45, 46]. Gupta et al. found lower patient-reported outcome scores in obese patients after hip arthroscopy specifically. They reported that these results were additionally accompanied by distinctly reduced preoperative scores, which in turn support this study's findings [47, 48]. Considering a large number of previous publications on this aspect, Saltzman et al. concluded that, despite clinical differences, there are no definite associations between BMI and outcome parameters owing to a variety of confounding variables [41]. Therefore, the role of BMI in the evaluation of baseline data needs to be investigated further. This study's fourth parameter associated with a significant reduction in the baseline iHOT-33 was the confirmation of previous surgeries on the affected hip. This is understandable as any surgical procedure has a certain failure rate that affects both the postoperative outcome and the preoperative scores in cases where revision surgery is performed. The statistical insignificance of the factors "defect grade," "defect size," "labral tears," and "symptom duration" was rather surprising. Here, outcome studies indicated further influence on the postoperative results, which we expected would be confirmed by our baseline analysis as well [13, 23, 39, 40, 49].

The findings of this study have to be seen in the light of some limitations. First, the study only assesses patients with cam-type FAI. Results might have been different 
for FAI patients in general including Pincer and combined Cam + Pincer morphologies. Then, as the used registry focuses on cartilage therapy, all patients were characterized by concomitant chondral defects. Again, results might have been different for patients with cam morphology in absence of cartilage damage. As patients with "previous surgery on the affected hip" were included in the statistical analysis, it can be questioned whether their data should be used when assessing baseline data. However, as none of the statistics were substantially changed hereby and as this aspect is of some importance, these patients were deliberately included in the study. Finally, the findings are based on the analysis of register data. Any parameters not evaluated (e.g., joint space or "Tönnies grade") or not (sufficiently) recorded by the register might have been unintentionally ignored or misinterpreted. Selection bias and non-response to followup questionnaires might also have led to biased results $[50,51]$.

\section{Conclusion}

The study revealed a distinct reduction in the baseline iHOT-33, with mean total scores being more than halved. The parameters "age $>40$ years," "female sex," "BMI $\geq 25 \mathrm{~kg} / \mathrm{m}^{2}$ ", and the confirmation of "previous surgery on the affected hip" were detected as associated with significantly lowered preoperative iHOT-33 scores. These findings help to identify symptom-defining baseline characteristics of cam-derived FAI syndrome. Moreover, as these factors have previously been identified to be associated with poorer postoperative outcome, additional information on chances and expectations of surgical FAI treatment for physicians and patients is provided.

\begin{abstract}
Abbreviations
FAl: Femoroacetabular impingement syndrome; iHOT-33: International Hip Outcome Tool (33 items); BMI: Body mass index; PROM: Patient-reported outcome measure; ICRS: International Cartilage Repair Society; SD: Standard deviation; Cl: Confidence interval; WHO: World Health Organization; PAS: Patient acceptable symptomatic state; PROMI: Patient-Reported Outcomes Measurement Information System; MCl: Minimal clinically important difference.
\end{abstract}

\section{Acknowledgements}

We thank Professor Stefan Wagenpfeil for providing statistical advice throughout the study conduct. We acknowledge support by the Deutsche Forschungsgemeinschaft (DFG, German Research Foundation) and Saarland University within the funding programme Open Access Publishing.

\section{Authors' contributions}

All authors contributed to the conception and design of the study. All authors were responsible for acquisition of data. S.S., M.S., and S.L. contributed to analysis and interpretation of data. All authors have read and approved the final manuscript.

\section{Funding}

Open Access funding enabled and organized by Projekt DEAL. This research received no specific grant from any funding agency in the public, commercial, or not-for-profit sectors.

\section{Availability of data and materials}

The data that support the findings of this study are available from the corresponding author upon reasonable request.

\section{Declarations}

\section{Ethics approval and consent to participate}

The German Cartilage Registry is conducted in accordance with the Declaration of Helsinki and registered at germanctr.de (DRKS00005617). The registration of data was approved by the local ethics committees of every participating institution. Primary approval was given by the ethics committee at the University of Freiburg (No. 105/13). Informed consent was obtained from all patients enrolled in this study.

\section{Consent for publication}

Written informed consent for publication was obtained.

\section{Competing interests}

The authors declare that there is no conflict of interest.

\section{Author details}

${ }^{1}$ Department of Orthopaedics \& Orthopaedic Surgery, Saarland University Medical Centre, Kirrberger Strasse 100, 66421 Homburg, Germany. ${ }^{2}$ Department of Orthopaedics \& Traumatology, University of Duisburg-Essen, Essen, Germany. ${ }^{3}$ Sporthopaedicum Straubing, Straubing, Germany. ${ }^{4}$ Department of Orthopaedic Surgery and Traumatology, Mannheim University Hospital, Mannheim, Germany. ${ }^{5} \mathrm{OCM}$ Clinic, Munich, Germany. ${ }^{6}$ Department of Orthopaedics and Trauma Surgery, Freiburg University Hospital, Freiburg im Breisgau, Germany. ${ }^{7}$ ARCUS Sports Clinic, Pforzheim, Germany. ${ }^{8}$ Center of Trauma and Orthopaedic Surgery and Jena University Hospital, Jena, Germany.

${ }^{9}$ Department of Orthopaedic Surgery and Traumatology, St. Vinzenz-Hospital Dinslaken, Dinslaken, Germany.

Received: 17 April 2021 Accepted: 25 July 2021

Published online: 04 August 2021

\section{References}

1. Agricola R, Heijboer MP, Bierma-Zeinstra SMA et al (2013) Cam impingement causes osteoarthritis of the hip: a nationwide prospective cohort study (CHECK). Ann Rheum Dis 72:918-923. https://doi.org/10.1136/ annrheumdis-2012-201643

2. Clohisy JC, Dobson MA, Robison JF et al (2011) Radiographic structural abnormalities associated with premature, natural hip-joint failure. J Bone Joint Surg Am 93(Suppl 2):3-9. https://doi.org/10.2106/JBJS.J.01734

3. Doherty M, Courtney P, Doherty S et al (2008) Nonspherical femoral head shape (pistol grip deformity), neck shaft angle, and risk of hip osteoarthritis: a case-control study. Arthritis Rheum 58:3172-3182. https://doi.org/ 10.1002/art.23939

4. Ganz R, Parvizi J, Beck M et al (2003) Femoroacetabular impingement: a cause for osteoarthritis of the hip. Clin Orthop Relat Res. https://doi.org/ 10.1097/01.blo.0000096804.78689.c2

5. Agricola R, Bessems JHJM, Ginai AZ et al (2012) The development of Camtype deformity in adolescent and young male soccer players. Am J Sports Med 40:1099-1106. https://doi.org/10.1177/0363546512438381

6. Siebenrock KA, Ferner F, Noble PC et al (2011) The cam-type deformity of the proximal femur arises in childhood in response to vigorous sporting activity. Clin Orthop Relat Res 469:3229-3240. https://doi.org/10.1007/ s11999-011-1945-4

7. L'Hermette M, Polle G, Tourny-Chollet C et al (2006) Hip passive range of motion and frequency of radiographic hip osteoarthritis in former elite handball players. Br J Sports Med 40:45-49. https://doi.org/10.1136/bjsm. 2005.019026 
8. Schmitt H, Brocai DRC, Lukoschek M (2004) High prevalence of hip arthrosis in former elite javelin throwers and high jumpers: 41 athletes examined more than 10 years after retirement from competitive sports. Acta Orthop Scand 75:34-39. https://doi.org/10.1080/000164704100017 08060

9. Nepple JJ, Vigdorchik JM, Clohisy JC (2015) What is the association between sports participation and the development of proximal femoral cam deformity? A systematic review and meta-analysis. Am J Sports Med 43:2833-2840. https://doi.org/10.1177/0363546514563909

10. Morris WZ, Li RT, Liu RW et al (2018) Origin of cam morphology in femoroacetabular impingement. Am J Sports Med 46:478-486. https://doi. org/10.1177/0363546517697689

11. Speirs AD, Beaulé PE, Huang A et al (2017) Properties of the cartilage layer from the cam-type hip impingement deformity. J Biomech 55:78-84. https://doi.org/10.1016/j.jbiomech.2017.02.007

12. Pascual-Garrido C, Li DJ, Grammatopoulos G et al (2019) The pattern of acetabular cartilage wear is hip morphology-dependent and patient demographic-dependent. Clin Orthop Relat Res 477:1021-1033. https:// doi.org/10.1097/CORR.0000000000000649

13. Menge TJ, Briggs KK, Dornan GJ et al (2017) Survivorship and outcomes 10 years following hip arthroscopy for femoroacetabular impingement: labral debridement compared with labral repair. J Bone Joint Surg Am 99:997-1004. https://doi.org/10.2106/JBJS.16.01060

14. Domb BG, Yuen LC, Ortiz-Declet V et al (2017) Arthroscopic labral base repair in the hip: 5-year minimum clinical outcomes. Am J Sports Med 45:2882-2890. https://doi.org/10.1177/0363546517713731

15. Grantham WJ, Philippon MJ (2019) Etiology and pathomechanics of femoroacetabular impingement. Curr Rev Musculoskelet Med. https:// doi.org/10.1007/s12178-019-09559-1

16. Catelli DS, Ng KCG, Kowalski E et al (2019) Modified gait patterns due to cam FAl syndrome remain unchanged after surgery. Gait Posture 72:135-141. https://doi.org/10.1016/j.gaitpost.2019.06.003

17. Mohtadi NGH, Griffin DR, Pedersen ME et al (2012) The development and validation of a self-administered quality-of-life outcome measure for young, active patients with symptomatic hip disease: the International Hip Outcome Tool (iHOT-33). Arthroscopy 28:595-605. https://doi.org/10. 1016/j.arthro.2012.03.013

18. Baumann F, Weber J, Zeman F et al (2016) Validation of a German version of the International Hip Outcome Tool (G-iHOT33) according to the COSMIN checklist: how much improvement is clinically relevant? Arch Orthop Trauma Surg 136:83-91. https://doi.org/10.1007/s00402-015-2336-1

19. Li DH, Wang W, Li X et al (2017) Development of a valid simplified Chinese version of the International Hip Outcome Tool (SC-iHOT-33) in young patients having total hip arthroplasty. Osteoarthr Cartil 25:94-98. https://doi.org/10.1016/j.joca.2016.08.013

20. Ruiz-Ibán MA, Seijas R, Sallent A et al (2015) The international Hip Outcome Tool-33 (iHOT-33): multicenter validation and translation to Spanish. Health Qual Life Outcomes 13:62. https://doi.org/10.1186/ s12955-015-0255-z

21. Tijssen M, Tak I, Stubbe J et al (2018) Translation, cross-cultural adaptation, and validation of the Dutch International Hip Outcome Tool-33 (iHOT-33 $\mathrm{NL}$ ) in young, physically active individuals with symptomatic hip joint pathology. J Orthop Sports Phys Ther 48:289-298. https://doi.org/10. 2519/jospt.2018.7610

22. Dwyer MK, Green M, McCarthy JC (2015) Assessing outcomes following arthroscopic labral debridement-what can the IHOT-33 reveal? J Hip Preserv Surg 2:152-157. https://doi.org/10.1093/jhps/hnv022

23. Sogbein OA, Shah A, Kay J et al (2019) Predictors of outcomes after hip arthroscopic surgery for femoroacetabular impingement: a systematic review. Orthop J Sports Med 7:23259671 19848982. https://doi.org/10. 1177/2325967119848982

24. Byrd JWT, Bardowski EA, Jones KS (2018) Influence of Tönnis grade on outcomes of arthroscopic management of symptomatic femoroacetabular impingement. Arthroscopy 34:2353-2356. https://doi.org/10.1016/j. arthro.2018.03.021

25. Claßen T, Körsmeier K, Kamminga M et al (2016) Is early treatment of cam-type femoroacetabular impingement the key to avoiding associated full thickness isolated chondral defects? Knee Surg Sports Traumatol Arthrosc 24:2332-2337. https://doi.org/10.1007/s00167-014-3332-7

26. Cvetanovich GL, Weber AE, Kuhns BD et al (2018) Hip arthroscopic surgery for femoroacetabular impingement with capsular management: factors associated with achieving clinically significant outcomes. Am J Sports Med 46:288-296. https://doi.org/10.1177/0363546517739824

27. Nwachukwu BU, Chang B, Kahlenberg CA et al (2017) Arthroscopic treatment of femoroacetabular impingement in adolescents provides clinically significant outcome improvement. Arthroscopy 33:1812-1818. https://doi.org/10.1016/j.arthro.2017.04.008

28. Nwachukwu BU, Fields K, Chang B et al (2017) Preoperative outcome scores are predictive of achieving the minimal clinically important difference after arthroscopic treatment of femoroacetabular impingement. Am J Sports Med 45:612-619. https://doi.org/10.1177/0363546516 669325

29. Griffin DR, Dickenson EJ, Wall PDH et al (2018) Hip arthroscopy versus best conservative care for the treatment of femoroacetabular impingement syndrome (UK FASHION): a multicentre randomised controlled trial. The Lancet 391:2225-2235. https://doi.org/10.1016/50140-6736(18) 31202-9

30. Palmer AJR, Ayyar Gupta V, Fernquest S et al (2019) Arthroscopic hip surgery compared with physiotherapy and activity modification for the treatment of symptomatic femoroacetabular impingement: multicentre randomised controlled trial. BMJ 364:1185. https://doi.org/10.1136/bmj. 1185

31. Maxwell S, Pergaminelis N, Renouf J et al (2018) Identification of a Patient Acceptable Symptomatic State Score for the International Hip Outcome Tool in people undergoing hip arthroscopy. Arthroscopy 34:3024-3029. https://doi.org/10.1016/j.arthro.2018.06.049

32. Robinson PG, Maempel JF, Rankin CS et al (2020) Evaluation of the patient acceptable symptom state following hip arthroscopy using the 12 item international hip outcome tool. BMC Musculoskelet Disord 21:5. https:// doi.org/10.1186/s12891-019-3026-X

33. Bijnen FC, Feskens EJ, Caspersen CJ et al (1998) Age, period, and cohort effects on physical activity among elderly men during 10 years of followup: the Zutphen Elderly Study. J Gerontol A Biol Sci Med Sci 53:M235M241. https://doi.org/10.1093/gerona/53a.3.m235

34. Hallal PC, Andersen LB, Bull FC et al (2012) Global physical activity levels: surveillance progress, pitfalls, and prospects. Lancet 380:247-257. https:// doi.org/10.1016/S0140-6736(12)60646-1

35. Agricola R, Heijboer MP, Ginai AZ et al (2014) A cam deformity is gradually acquired during skeletal maturation in adolescent and young male soccer players: a prospective study with minimum 2-year follow-up. Am J Sports Med 42:798-806. https://doi.org/10.1177/0363546514524364

36. Palmer A, Fernquest S, Gimpel M et al (2018) Physical activity during adolescence and the development of cam morphology: a cross-sectional cohort study of 210 individuals. Br J Sports Med 52:601-610. https://doi. org/10.1136/bjsports-2017-097626

37. Bize R, Johnson JA, Plotnikoff RC (2007) Physical activity level and healthrelated quality of life in the general adult population: a systematic review. Prev Med 45:401-415. https://doi.org/10.1016/j.ypmed.2007.07.017

38. Nawabi DH, Bedi A, Tibor LM et al (2014) The demographic characteristics of high-level and recreational athletes undergoing hip arthroscopy for femoroacetabular impingement: a sports-specific analysis. Arthroscopy 30:398-405. https://doi.org/10.1016/j.arthro.2013.12.010

39. Saadat E, Martin SD, Thornhill TS et al (2014) Factors associated with the failure of surgical treatment for femoroacetabular impingement: review of the literature. Am J Sports Med 42:1487-1495. https://doi.org/10.1177/ 0363546513500766

40. Minkara AA, Westermann RW, Rosneck J et al (2019) Systematic review and meta-analysis of outcomes after hip arthroscopy in femoroacetabular impingement. Am J Sports Med 47:488-500. https://doi.org/10.1177/ 0363546517749475

41. Saltzman BM, Kuhns BD, Basques B et al (2017) The influence of body mass index on outcomes after hip arthroscopic surgery with capsular plication for the treatment of femoroacetabular impingement. Am J Sports Med 45:2303-2311. https://doi.org/10.1177/0363546517705617

42. Nwachukwu BU, Beck EC, Chapman R et al (2019) Preoperative performance of the PROMIS in patients undergoing hip arthroscopic surgery for femoroacetabular impingement syndrome. Orthop J Sports Med 7:2325967119860079. https://doi.org/10.1177/2325967119860079

43. Carrington JL (2005) Aging bone and cartilage: cross-cutting issues. Biochem Biophys Res Commun 328:700-708. https://doi.org/10.1016/j. bbrc.2004.12.041 
44. van der Kraan PM, van den Berg WB (2008) Osteoarthritis in the context of ageing and evolution. Loss of chondrocyte differentiation block during ageing. Ageing Res Rev 7:106-113. https://doi.org/10.1016/j.arr.2007.10. 001

45. Bech NH, Kodde IF, Dusseldorp F et al (2016) Hip arthroscopy in obese, a successful combination? J Hip Preserv Surg 3:37-42. https://doi.org/10. 1093/jhps/hnv076

46. Collins JA, Beutel BG, Garofolo G et al (2015) Correlation of obesity with patient-reported outcomes and complications after hip arthroscopy. Arthroscopy 31:57-62. https://doi.org/10.1016/j.arthro.2014.07.013

47. Gupta A, Redmond JM, Hammarstedt JE et al (2015) Does obesity affect outcomes in hip arthroscopy? A matched-pair controlled study with minimum 2-year follow-up. Am J Sports Med 43:965-971. https://doi.org/ $10.1177 / 0363546514565089$

48. Gupta A, Redmond JM, Hammarstedt JE et al (2015) Does obesity affect outcomes after hip arthroscopy? A cohort analysis. J Bone Joint Surg Am 97:16-23. https://doi.org/10.2106/JBJS.N.00625
49. Kunze KN, Nwachukwu BU, Beck EC et al (2019) Preoperative duration of symptoms is associated with outcomes 5 years after hip arthroscopy for femoroacetabular impingement syndrome. Arthroscopy. https://doi.org/ 10.1016/j.arthro.2019.08.032

50. Maurer J, Grotejohann B, Jenkner C et al (2016) A registry for evaluation of efficiency and safety of surgical treatment of cartilage defects: the German Cartilage Registryn(KnorpelRegister DGOU). JMIR Res Protoc 5:e122. https://doi.org/10.2196/resprot.5895

51. Imam MA, Barke S, Stafford GH et al (2014) Loss to follow-up after total hip replacement: a source of bias in patient reported outcome measures and registry datasets? Hip Int 24:465-472. https://doi.org/10.5301/hipint. 5000141

\section{Publisher's Note}

Springer Nature remains neutral with regard to jurisdictional claims in published maps and institutional affiliations.

\section{Submit your manuscript to a SpringerOpen ${ }^{\circ}$ journal and benefit from:}

- Convenient online submission

- Rigorous peer review

- Open access: articles freely available online

- High visibility within the field

- Retaining the copyright to your article

Submit your next manuscript at $>$ springeropen.com 